\title{
Mortality in first- and second-generation immigrants to Sweden diagnosed with type 2 diabetes: a 10 year nationwide cohort study
}

\author{
Louise Bennet ${ }^{1,2}$ (D) $\cdot$ Ruzan Udumyan ${ }^{3}$ (D) $\cdot$ Carl Johan Östgren ${ }^{4}$ (D) $\cdot$ Olov Rolandsson $^{5}$ (D) Stefan P. O. Jansson ${ }^{6,7}$ (D) \\ Per Wändell ${ }^{8}$
}

Received: 26 March 2020 / Accepted: 11 August 2020 / Published online: 26 September 2020

(C) The Author(s) 2020

\begin{abstract}
Aims/hypothesis Non-Western immigrants to Europe are at high risk for type 2 diabetes. In this nationwide study including incident cases of type 2 diabetes, the aim was to compare all-cause mortality (ACM) and cause-specific mortality (CSM) rates in first- and second-generation immigrants with native Swedes.

Methods People living in Sweden diagnosed with new-onset pharmacologically treated type 2 diabetes between 2006 and 2012 were identified through the Swedish Prescribed Drug Register. They were followed until 31 December 2016 for ACM and until 31 December 2012 for CSM. Analyses were adjusted for age at diagnosis, sex, socioeconomic status, education, treatment and region. Associations were assessed using Cox regression analysis.

Results In total, 138,085 individuals were diagnosed with type 2 diabetes between 2006 and 2012 and fulfilled inclusion criteria. Of these, 102,163 (74.0\%) were native Swedes, 28,819 (20.9\%) were first-generation immigrants and $7103(5.1 \%)$ were secondgeneration immigrants with either one or both parents born outside Sweden. First-generation immigrants had lower ACM rate (HR 0.80 [95\% CI 0.76, 0.84]) compared with native Swedes. The mortality rates were particularly low in people born in nonWestern regions ( 0.46 [0.42, 0.50]; the Middle East, 0.41 [0.36, 0.47]; Asia, 0.53 [0.43, 0.66]; Africa, 0.47 [0.38, 0.59]; and Latin America, $0.53[0.42,0.68])$. ACM rates decreased with older age at migration and shorter stay in Sweden. Compared with native Swedes, first-generation immigrants with $\leq 24$ years in Sweden $(0.55[0.51,0.60])$ displayed lower ACM rates than those spending $>24$ years in Sweden $(0.92$ [0.87, 0.97]). Second-generation immigrants did not have better survival rates than native Swedes but rather displayed higher ACM rates for people with both parents born abroad $(1.28[1.05,1.56])$.

Conclusions/interpretation In people with type 2 diabetes, the lower mortality rate in first-generation non-Western immigrants compared with native Swedes was reduced over time and was equalised in second-generation immigrants. These findings suggest that acculturation to Western culture may impact ACM and CSM in immigrants with type 2 diabetes but further investigation is needed.
\end{abstract}

Stefan P. O. Jansson and Per Wändell are joint senior authors.

Electronic supplementary material The online version of this article (https://doi.org/10.1007/s00125-020-05279-1) contains peer-reviewed but unedited supplementary material, which is available to authorised users.

Louise Bennet

louise.bennet@med.lu.se

1 Department of Clinical Sciences in Malmö, Lund University, Malmö, Sweden

2 Department of Family Medicine, Lund University, Malmö, Sweden

3 Clinical Epidemiology and Biostatistics, School of Medical Sciences, Örebro University, Örebro, Sweden

4 Department of Health, Medicine and Caring Sciences, General Practice, Linköping University, Linköping, Sweden
5 Department of Public Health and Clinical Medicine, Family Medicine, Umeå University, Umeå, Sweden

6 Institution of Medical Sciences, University Health Care Research Center, Örebro University, Örebro, Sweden

7 Department of Public Health and Caring Sciences, Uppsala University, Uppsala, Sweden

8 Department of Neurobiology, Care Sciences and Society, Karolinska Institutet, Huddinge, Sweden 


\section{Research in context}

What is already known about this subject?

- Non-European immigrants are at high risk for type 2 diabetes and diabetes complications

- Non-European immigrants have an earlier diabetes onset than native Scandinavians

What is the key question?

- Do individuals with type 2 diabetes born abroad, or with one or both parents born abroad, have higher all-cause $(\mathrm{ACM})$ and cause-specific mortality (CSM) rates than native Swedish individuals?

What are the new findings?

- $\quad$ First-generation non-Western immigrants had lower rates of ACM and CSM than native Swedes diagnosed with type 2 diabetes

- First-generation immigrants with $>24$ years in Sweden had higher ACM rates than those with shorter duration of stay

- Second-generation immigrants did not have better survival rates than native Swedes but rather displayed higher rates of $A C M$ in those with both parents born abroad

How might this impact on clinical practice in the foreseeable future?

- Our data indicate that, in individuals with type 2 diabetes, exposure to the Swedish environment seems to have a larger impact on mortality rate than region of origin. The influence of a non-Western environment may have a protective impact on survival

Keywords All-cause mortality · Cause-specific mortality · First-generation · Immigrants · Incident · Non-Western · Second-generation $\cdot$ Survival $\cdot$ Type 2 diabetes

\author{
Abbreviations \\ ACM All-cause mortality \\ ATC Anatomical Therapeutic Chemical \\ CSM Cause-specific mortality \\ EU28 European Union (EU) countries including the UK \\ LISA Swedish acronym for Longitudinal Database of \\ Education, Income and Occupation \\ NDR National Diabetes Register
}

\section{Introduction}

Type 2 diabetes is a complex chronic metabolic disease affecting a large proportion of the global population, particularly populations originating from South Asia, the Middle East and North Africa [1]. Type 2 diabetes influences the cardiovascular, renal and nervous systems, and contributes to increased morbidity due to macro- and microvascular complications and, subsequently, premature death [2].

Non-Western immigrants to Europe constitute a growing proportion of the recipient countries, and are at very high risk for developing type 2 diabetes [3, 4]. This increased risk is often attributed to genetic factors including epigenetics $[5,6]$, but environmental factors such as unfavourable lifestyle, obesity, poor socioeconomic situation, and cultural and social norms [7, 8] contribute even more [9]. A poor socioeconomic situation is strongly associated with poor lifestyle, e.g. intake of energy-dense foods and drinks, and a sedentary lifestyle [8]. A large proportion of non-Western immigrants to Sweden live in socioeconomically vulnerable neighbourhoods [1]. A previous Swedish longitudinal cohort study showed that refugees to Sweden referred to live in socioeconomically vulnerable areas developed diabetes to a greater extent than those referred to live in less vulnerable areas, reflecting the strong impact of socioeconomic status on type 2 diabetes risk [10].

Data based on the Swedish National Diabetes Register (NDR) have shown that although non-Western immigrants with type 2 diabetes attend more visits to their doctors, their metabolic control is worse and the risk of diabetic complications such as nephropathy is higher [11]. This indicates that mechanisms other than access to healthcare services influence disease trajectories. Interestingly, data from the NDR have paradoxically shown that non-Western first-generation immigrants had lower mortality rates than native Swedes [12].

Population-based studies of immigrant populations in Europe show a mortality advantage in first-generation immigrants that over time converges to the level of natives [13-15]; 
however, we have not found any studies of people with type 2 diabetes comparing mortality in first- and second-generation immigrants with natives.

In this study including all people with type 2 diabetes in Sweden identified through the Swedish Prescribed Drug Register, we aimed to compare all-cause mortality (ACM) and cause-specific mortality (CSM) rates between first-generation immigrants from different regions and native Swedes. Our secondary aim was to investigate the impact of time since migration on ACM. Our third aim was to compare ACM and CSM rates in second-generation immigrants and native Swedes.

\section{Methods}

Study population and data sources Individuals with incident type 2 diabetes were identified from the Swedish Prescribed Drug Register, which was initiated in July 2005 [16]. The study population selection procedure has been described in a previous publication [17]. Briefly, people with type 2 diabetes were included if they initiated a glucose-lowering pharmacological treatment for type 2 diabetes dispensed at Swedish pharmacies sometime between 1 July 2006 and 30 June 2012. In correspondence with previous studies, people diagnosed between 30 and 75 years of age were included in the study $[12,18]$.

The Prescribed Drug Register was also used to identify and classify the received glucose-lowering treatments using Anatomical Therapeutic Chemical (ATC) classification codes by the WHO.

The LISA (Swedish acronym for Longitudinal Database of Education, Income and Occupation) register [19] was used to obtain information on Swedish vs non-Swedish background, whereby participants were classified into: (1) 'native Swedes', defined as those who, along with their parents, were born in Sweden; (2) 'first-generation immigrants' if born outside of Sweden to foreign-born parents; or (3) 'second-generation immigrants' if born in Sweden to one or two foreign-born parents. The LISA register also provided information on the country of birth, the highest educational level, disposable income, occupation and municipality of residence at diabetes diagnosis. The Swedish Cause of Death Register [20] provided information on the date and underlying cause of death, the latter recorded until 2012. Information on migration date and type of migration (immigration or emigration) was obtained from Statistics Sweden [1].

Definition of non-Western origin Individuals born in the Middle East, Asia, Africa, Latin America or the Caribbean were considered as having non-Western origin. Individuals born in the other countries but Sweden (reference) were considered as having Western origin.

Definition of type 2 diabetes Incident cases of diabetes were classified as 'type 1' or 'type 2' on the basis of glucose- lowering treatment received within 1 year after diagnosis date (electronic supplementary material [ESM] Table 1). Diabetes was classified as type 1 if treatment was by rapid-acting insulin (A10AB) solely or in combination with intermediate- or long-acting insulin (A10AC, A10AE).

Diabetes was classified as type 2 if glucose-lowering medications (GLMs) listed under the ATC A10B code were prescribed solely or in combination with insulin (A10AB, A10AC, A10AE, A10AD) (ESM Table 1). Participants who only received intermediate- or long-acting insulin were considered non-insulin-dependent and were classified as having type 2 diabetes. Correspondingly, those treated with mixed-insulin (A10AD) with or without combination with rapid-, intermediate- or long-acting insulin (A10AB, A10AC, A10AE) were also classified as having type 2 diabetes.

Outcome assessment The primary outcome was time to ACM. Participants' follow-up started 1 year after the date of diabetes diagnosis, defined as the date of the first dispensed glucoselowering drug, and continued until date of emigration, death or study end (31 December, 2016), whichever came first. In a secondary analysis, we assessed cancer-specific (ICD-10 codes C00-C97) and cardiovascular disease (ICD-10 codes I00-I99)related mortality. Individuals were followed for CSM until 31 December, 2012, since the information on the underlying cause of death was available until the end of 2012.

Statistical analysis Patient characteristics were tabulated by country of birth. Cox proportional hazards regression models with time since diagnosis in years as the underlying time scale were fitted to assess survival differences between immigrants and native Swedes. The multivariable fractional polynomials method [21] assessed the functional form of continuous variables in the log-hazard function. Test and plots of Schoenfeld residuals evaluated the proportional hazards assumption, which was satisfied for migration status and country of birth of both first- and second-generation immigrants.

Separate analyses were conducted to estimate HRs and 95\% CIs for the associations between migration status and mortality in the entire study population, as well as between country of birth and mortality for first- and second-generation immigrants. First-generation immigrants' country of birth was categorised into the following groups: Africa; EU countries including the UK (EU28) except Nordic countries; Europe; Nordic other than Sweden; the Middle East; Asia; Latin America; and North America. Second-generation immigrants' country of origin was categorised on the basis of their parents' country of birth into the following groups: Nordic; European but not Nordic; North American; and non-Western, with each group reflecting an increasing gradient of non-Western origin. If parents came from different regions, we emphasised the parent with the highest degree of non-Western origin. Therefore, an individual with one parent from Sweden and 
one from the Baltic countries was classified as 'European but not Nordic', and an individual with one parent from Germany and one from Iraq was classified as 'non-Western'.

Multivariable Cox regression models were adjusted for age at diabetes diagnosis, sex, attained education, disposable income, occupational socioeconomic group, region of residence and type of diabetes treatment. Age was modelled using restricted cubic splines with three knots. Knot locations were based on Harrell's recommended percentiles [22]. Attained education at diabetes diagnosis was categorised by duration into compulsory (up to 9 years), secondary (10-12 years) and post-secondary (more than 12 years). Municipality of residence was categorised into living in small cities $(<200,000$ inhabitants) and larger cities ( $\geq 200,000$ inhabitants). Individuals' disposable income was divided into quintiles for descriptive statistics and modelled using restricted cubic splines with three knots for multivariable analyses. Occupational socioeconomic group was categorised into clerks, office holders and officials; other occupational workers; and non-employed. Participants over 67 years of age were classified as retired. Type 2 diabetes treatment was classified into insulin monotherapy; sulfonylureas/repaglinide monotherapy; metformin monotherapy; insulin and tablets; metformin and sulfonylureas/repaglinide; metformin and other tablets; and other monotherapies or drug combinations (ESM Table 2).

Multiplicative interaction terms were added to the adjusted model to test whether associations between regions of birth of first-generation immigrants and ACM differ by sex, age at diabetes diagnosis, disposable income and type 2 diabetes treatment. We also present the marginal plots of the effects of age at diagnosis and disposable income on ACM by region of birth (Figs. 3, 4).

Further analyses assessed the role of age at immigration and duration of residence in Sweden for the first-generation immigrants using native Swedes as the reference population. Age at immigration to Sweden was categorised into $\leq 21,>21$ to $\leq 28,>28$ to $\leq 38$ and $>38$ years according to quartiles of the distribution. Duration of stay in Sweden was classified into $\leq 24$ and $>24$ years (median duration of residence of firstgeneration immigrants $=24.2$ years).

All calculations were performed using STATA software version 14SE (StataCorp, College Station, TX, USA).

Ethical considerations The Regional Research Ethics Board in Uppsala, Sweden approved the study.

\section{Results}

The analysis is based on 138,085 people with type 2 diabetes who fulfilled inclusion criteria. Over a total observation period of about 833,095 person-years (median follow-up $=6.0$ years, maximum follow-up $=9.5$ years), 14,614 people died.
Table 1 shows characteristics of the study groups according to region of birth. The mean age at type 2 diabetes diagnosis in native Swedes was approximately 4 years greater than in firstgeneration immigrants and 7 years greater than in secondgeneration immigrants (Table 1). The earliest diabetes onsets were observed in immigrants originating from Africa, Asia and the Middle East. In first-generation immigrants, socioeconomic vulnerability differed considerably according to region of origin; approximately $50 \%$ of individuals originating from Africa, the Middle East and Asia had disposable income in the lowest quintile, whereas less than $15 \%$ of individuals originating from Sweden were within this income level. Further, immigrants were to a higher extent $(>40 \%)$ non-employed, with the highest rates in Middle Eastern immigrants. Paradoxically, the education level was higher in individuals of non-Swedish origin. In secondgeneration immigrants disposable income, as well as education level, was on a par with that of native Swedes.

Table 2 presents age-adjusted and multivariable-adjusted Cox regression analyses for ACM and CVD- and cancerrelated mortality in relation to migration status, and country of birth of first-generation immigrants as well as parents' country of birth of second-generation immigrants. Multivariableadjusted analyses suggested lower ACM and CVD mortality rates for first-generation immigrants compared with native Swedes. Further, first-generation immigrants originating from Africa, Asia, the Middle East and Latin America had considerably higher overall survival rates (Fig. 1, Table 2) and lower CVD mortality rates (Table 2) than native Swedes. Immigrants born in the Middle East had considerably lower cancer-related mortality rates compared with native Swedes (Table 2). ACM and CSM rates in non-Western first-generation immigrants were considerably lower compared with native Swedes (HRs: ACM 0.46 [0.42, 0.50]; CVD 0.37 [0.27, 0.50]; and cancerspecific mortality $0.70[0.55,0.90]$ ) (ESM Table 3). Mortality rates (ACM or CSM) did not differ between individuals of Western origin and native Swedes.

While first-generation immigrants had lower all-cause and CVD mortality rates, second-generation immigrants had higher overall mortality rates than native Swedes (Table 2, entire population, Fig. 2). In the analyses classifying secondgeneration immigrants according to parents' country of birth, the adjusted HRs were largely statistically non-significant, except for second-generation immigrants with parents born in the Nordic countries, presenting almost $50 \%$ higher hazards for cancer-related mortality (Table 2, parents' country of birthspecific data).

Associations by age at immigration to Sweden of firstgeneration immigrants are displayed in Table 3 , and by duration of residence in Sweden in Table 4. First-generation nonWestern immigrants with older age at migration had generally higher-magnitude inverse association with ACM than those with younger age at migration (Table 3). Overall, higher magnitude inverse association was observed for first- 


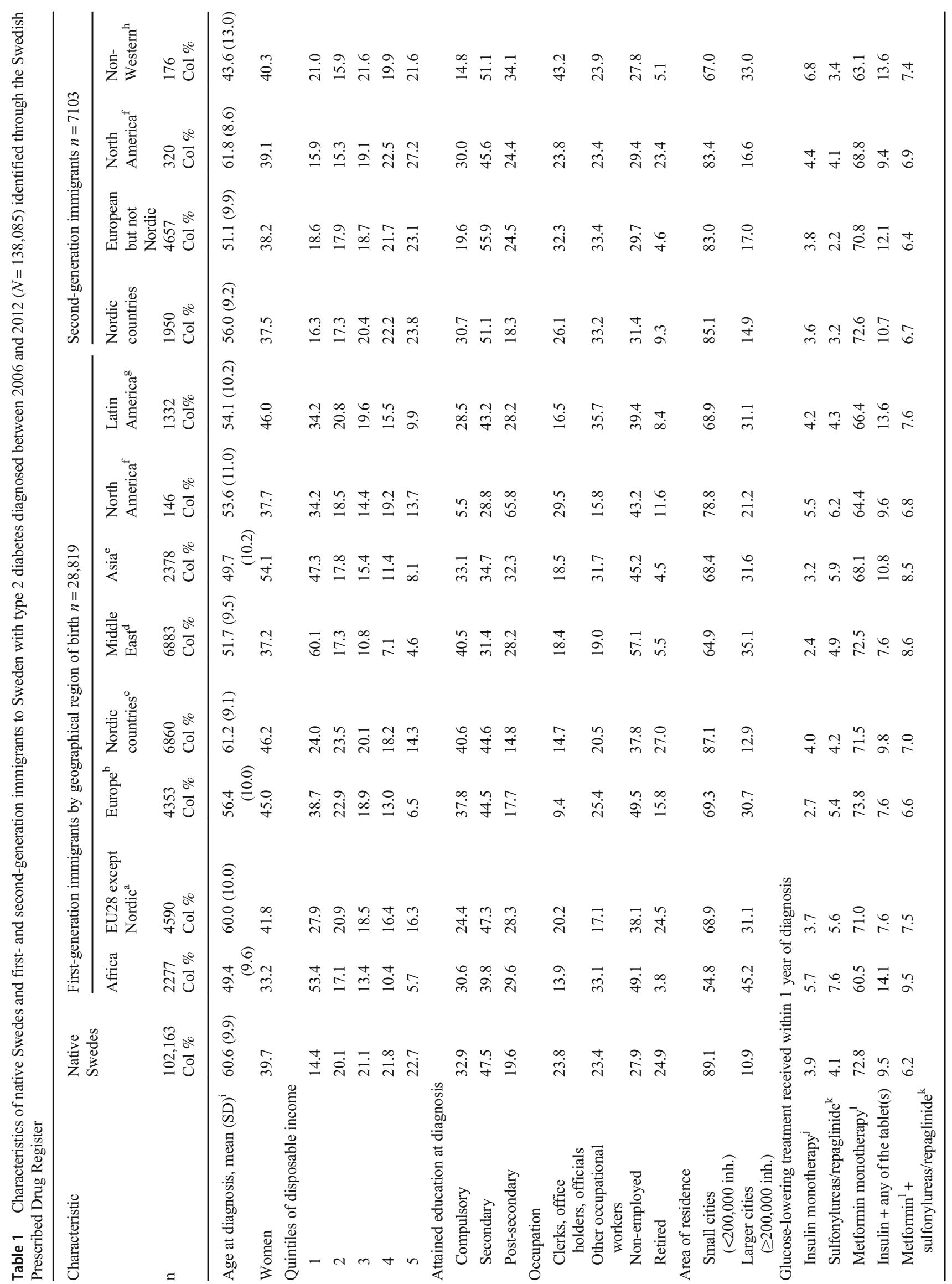




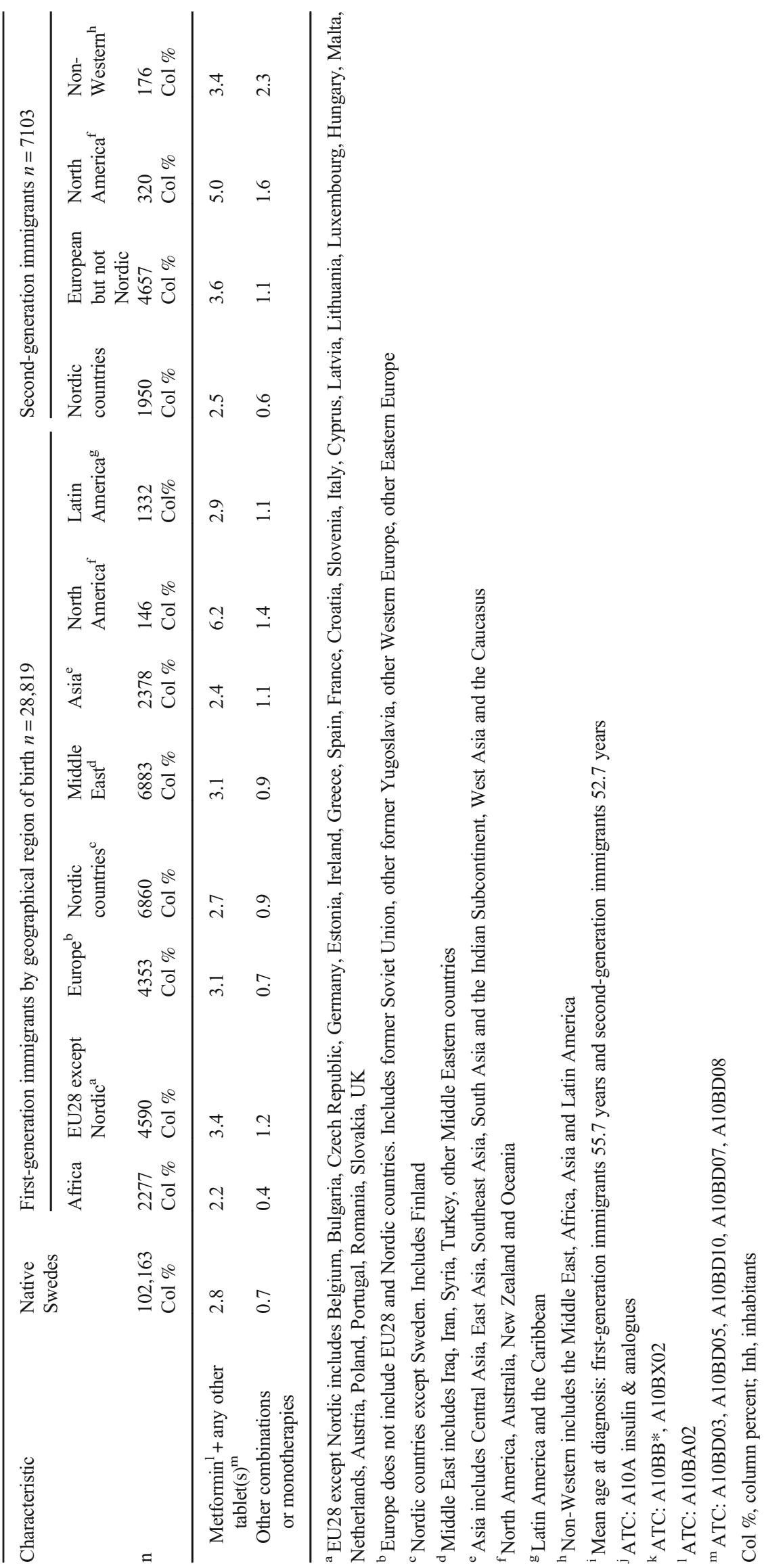




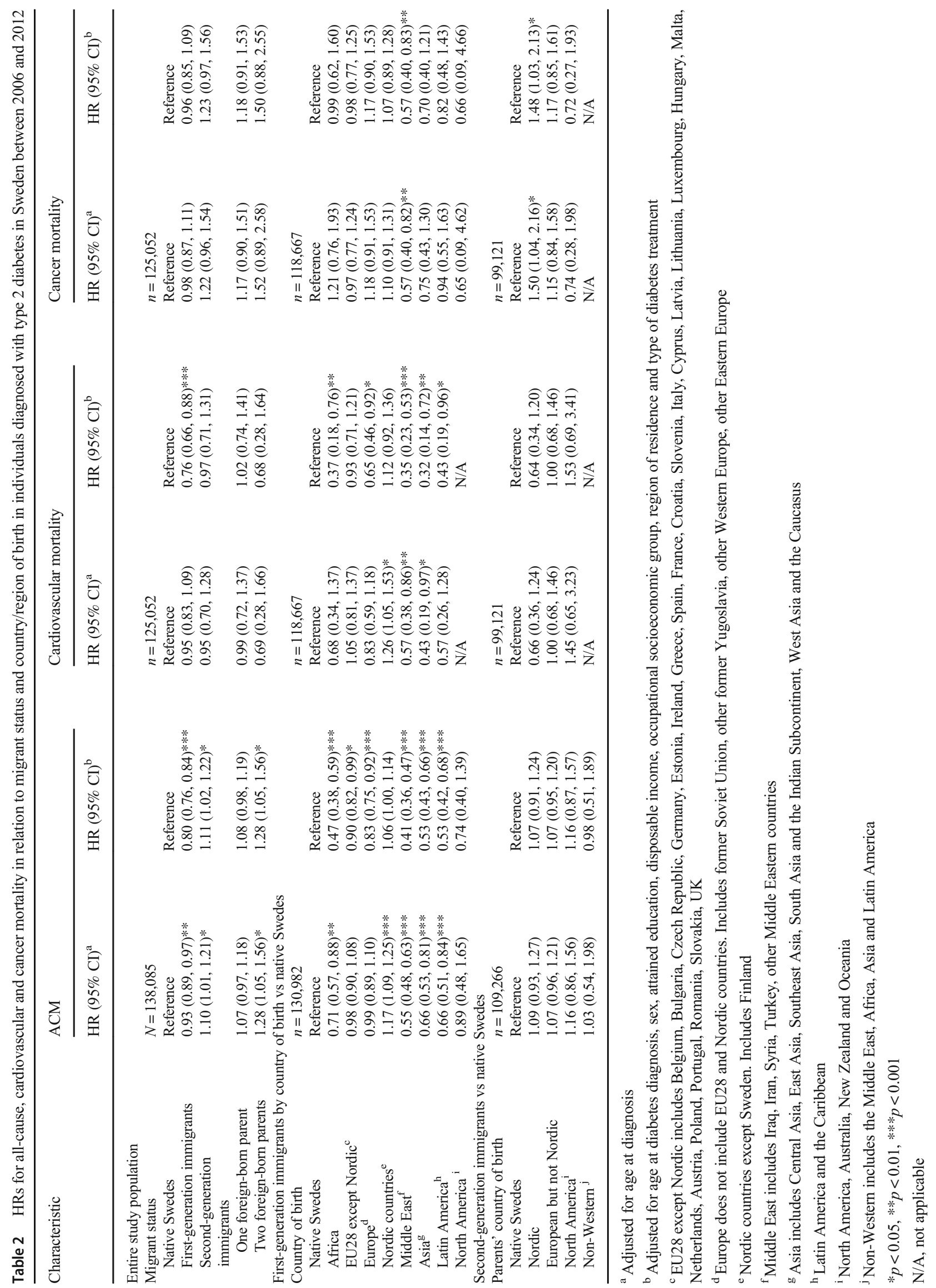




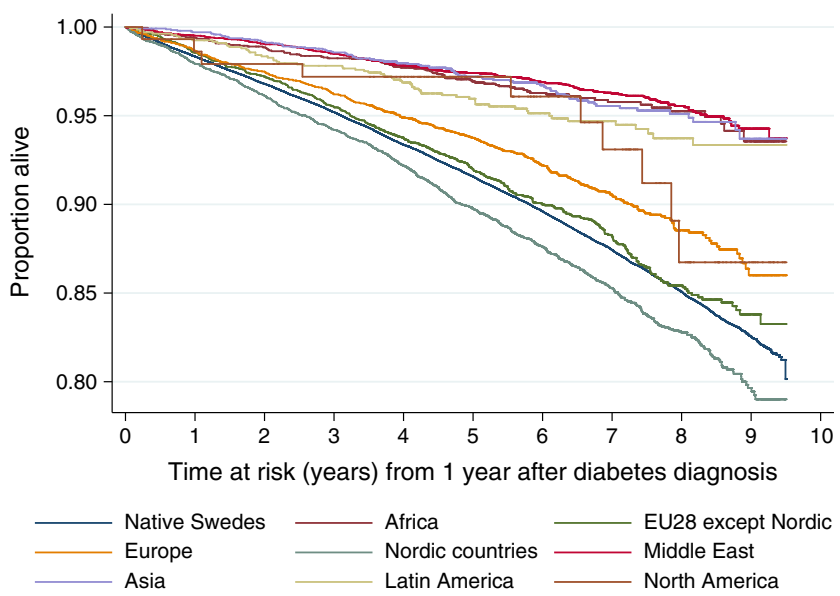

Fig. 1 Kaplan-Meier survival estimates for native Swedes and firstgeneration immigrants with type 2 diabetes by their country/region of birth

generation immigrants with $\leq 24$ years in Sweden than for those spending $>24$ years in Sweden (Table 4).

The interaction terms with spline transformations of age and income were statistically significant $(p$ values $<0.001$ ), suggesting that older age at diagnosis generally was associated with higher relative hazard, while higher disposable income was associated with lower relative hazard, although somewhat different shapes of functions were observed across region of birth of the first-generation immigrants (Figs. 3, 4).

The interactions terms with sex and type 2 diabetes treatment were not statistically significant ( $\mathrm{p}$ values were 0.287 and 0.169 , respectively), suggesting that the associations did not differ for men and women or across the treatment strategies.

\section{Discussion}

To the best of our knowledge, this is one of the first studies investigating survival rates in first- as well as second-generation

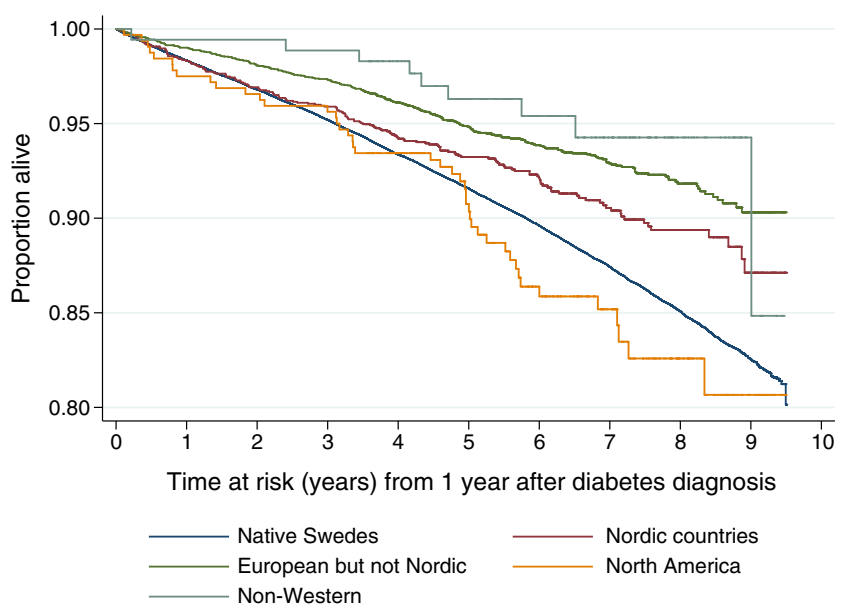

Fig. 2 Kaplan-Meier survival estimates for native Swedes and secondgeneration immigrants with type 2 diabetes by their parents' country/ region of birth immigrants with type 2 diabetes. In this 10 year follow-up study, we show that first-generation non-Western immigrants have substantially lower ACM as well as CSM rates compared with native Swedes with type 2 diabetes. Further, we found that the younger the age at migration and the longer the duration of stay in Sweden, the larger the risk of shorter survival. For secondgeneration immigrants we did not observe beneficial survival rates compared with native Swedes, but rather, in particular in those with both parents born outside Sweden, they presented with shorter survival. Altogether, our study shows that firstgeneration non-Western immigrants at the early stage of migration initially are protected and display a mortality advantage over native Swedes, but, over time, in first-generation immigrants the lower mortality is subsequently reduced, and in secondgeneration immigrants is equalised.

The observed mortality advantage in first-generation immigrants has been reported previously. Data from the NDR report lower mortality rates in first-generation non-Western immigrants than the native Swedish-born population with diabetes [12]. Further, a Canadian long-term follow-up study, from 2005 to 2012, showed lower ACM and CVD-related mortality rates in first-generation immigrants with diabetes, an effect that persisted more than 10 years after immigration [23]. However, we have not found studies of mortality including first- as well as second-generation people with diabetes. Studies of the general population have shown that the health advantages in first-generation non-Western immigrants to Western countries erode over time [24, 25]. For instance, studies conducted in France, Belgium and Norway show lower ACM in first-generation immigrants, but, with duration of stay, the ACM converges towards that of natives [13-15], as we observe in our study. Contributing mechanisms may be connected to the influence of lifestyle, acculturation to the Western culture and epigenetics, but need further investigation.

The observed early diabetes onset and poor socioeconomic situation correspond with previous studies conducted in Sweden and Norway [26, 27]. It was previously shown that younger age at diabetes onset increases the risk of ACM [28], and that poor socioeconomic status with unemployment and lack of integration contributes to type 2 diabetes risk in nonWestern immigrants to Sweden $[9,10]$. Further, poor health literacy aggregates in socioeconomically vulnerable minority groups and is, according to the WHO, one of the most important determinants of health which contributes to high morbidity rates [29]. However, our data show important interactions among region of birth, age at onset and socioeconomic status (Figs. 3, 4). Our findings indicate that, in first-generation immigrants of non-Western origin, earlier age at onset, as well as low income, does not impact survival to as high an extent as in people with diabetes of Swedish or Western origin, and may partly explain the observed mortality paradox.

ACM in type 2 diabetes is mainly driven by complications in CVD [30]. Population-based studies have shown that Asian 


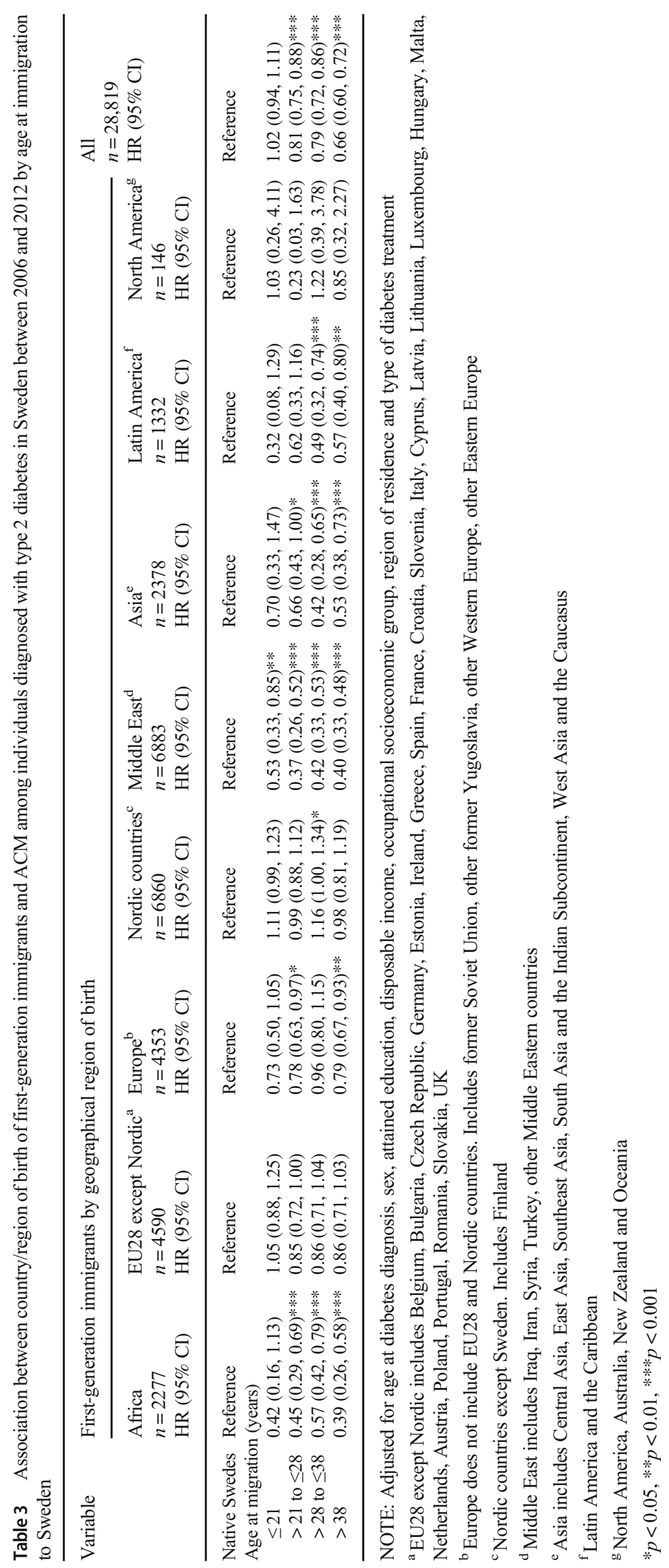




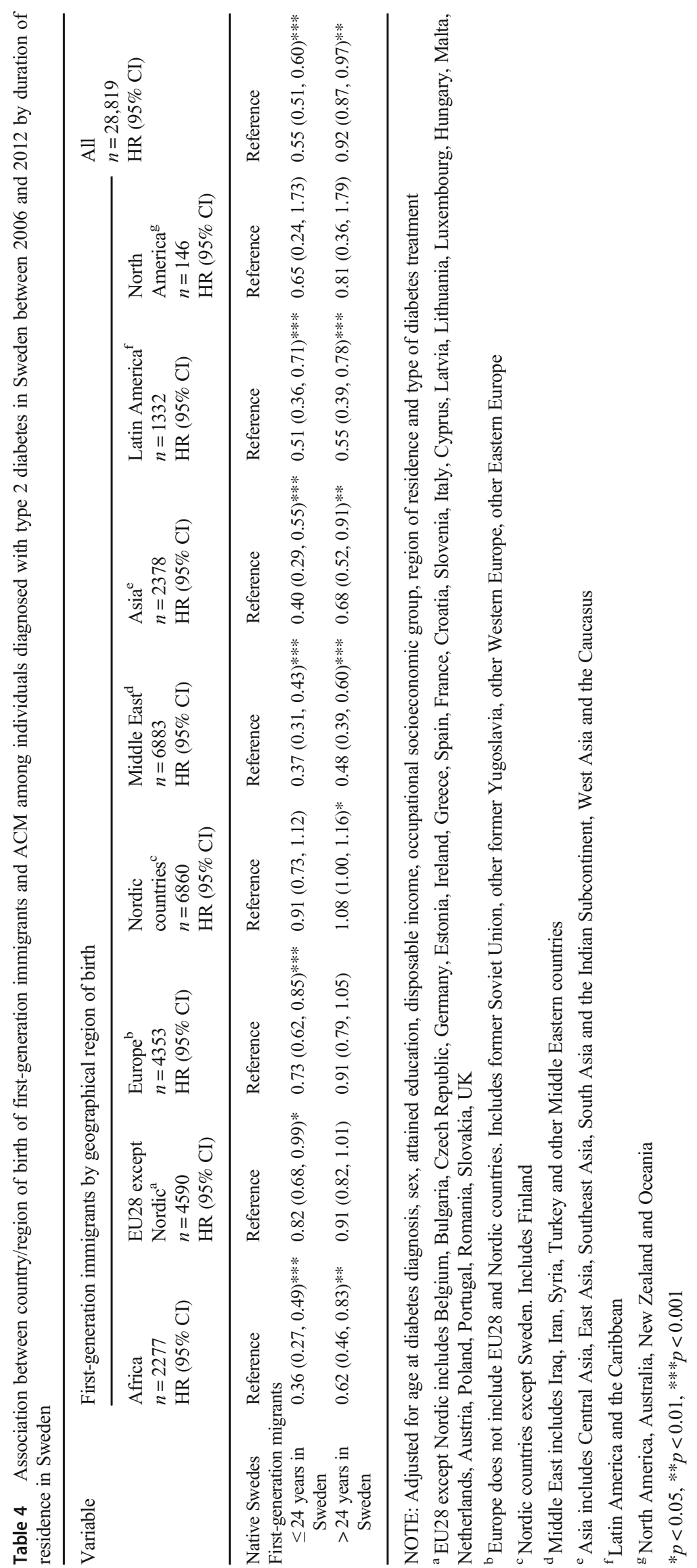




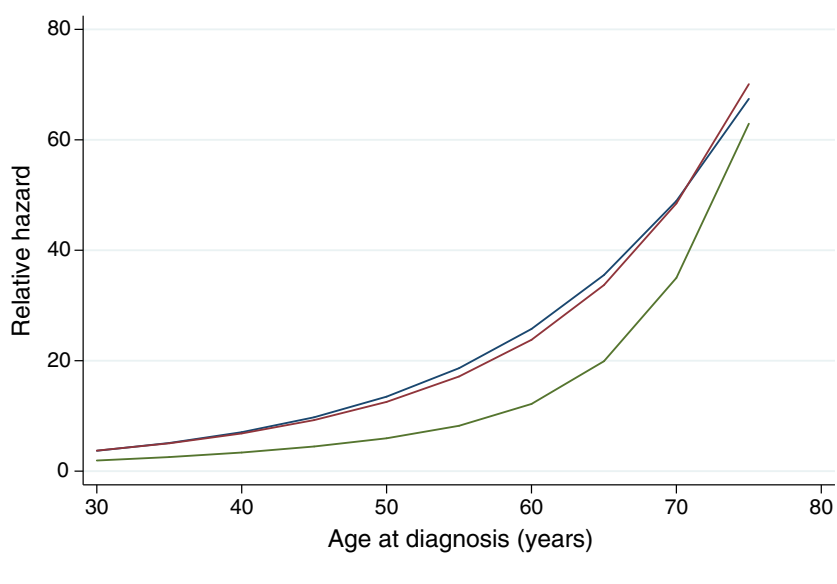

Fig. 3 Marginal effect of age at diagnosis on the relative hazard of ACM in a Cox model by region of birth in the sample including native Swedes and first-generation immigrants diagnosed with type 2 diabetes in Sweden between 2006 and 2012. The model includes multiplicative interaction of region of birth and spline transformations of age, and multiplicative interaction of region of birth and spline transformations of disposable income, attained education, occupational socioeconomic group, region of residence and type of diabetes treatment

and Middle Eastern populations are not exposed to hypertension to the same extent as the native Nordic populations [31, 32]. The lower risk of hypertension may theoretically contribute to the observed lower CVD morbidity and mortality rates in the firstgeneration non-Western diabetes population, but this needs to be investigated further. Obesity, sedentary lifestyle and family history of diabetes are strong contributors to diabetes risk [33] and are highly prevalent in Middle Eastern and South Asian immigrant populations $[3,26]$. It is reported that people diagnosed with mild obesity-related diabetes have lower risk of

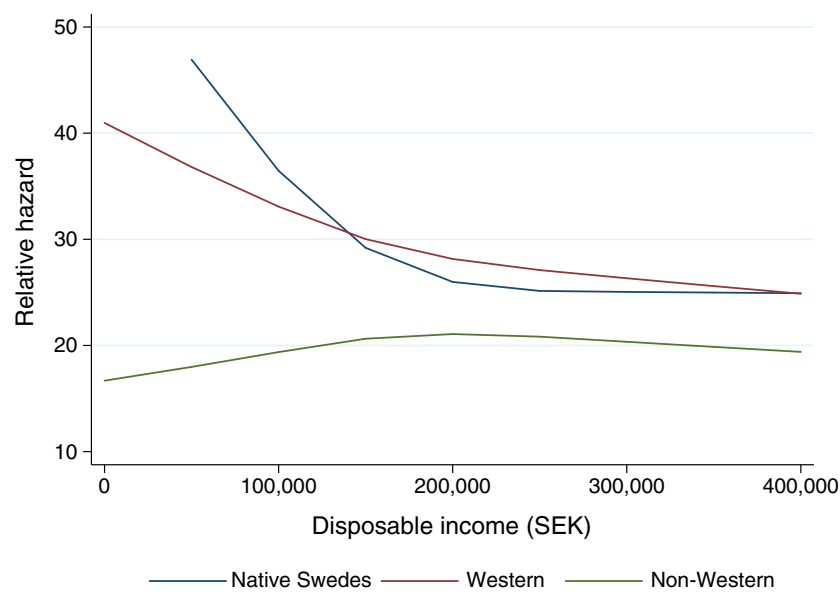

Fig. 4 Marginal effect of disposable income on the relative hazard of ACM in a Cox model by region of birth in the sample including native Swedes and first-generation immigrants diagnosed with type 2 diabetes in Sweden between 2006 and 2012. The model includes multiplicative interaction of region of birth and spline transformations of disposable income, and multiplicative interaction of region of birth and spline transformations of age, attained education, occupational socioeconomic group, region of residence and type of diabetes treatment developing CVD-related complications [34]. Further, lower mortality rates are reported in obese people with type 2 diabetes, not only compared with the extremely obese, but also, paradoxically, compared with normal weight individuals with type 2 diabetes [35], indicating that 'healthy obesity' may influence the differences in mortality rates [36]. We have previously shown that first-generation Middle Eastern immigrants to Sweden present a more favourable fat profile than native Swedes, hypothetically protecting them from hypertension and CVD [37]. Thus, acculturation over time to Western lifestyle habits, with less-favourable fat intake, may contribute to the loss of mortality advantage in second-generation immigrants.

The beneficial cancer survival rates observed in firstgeneration non-Western immigrants (in particular, Middle Eastern immigrants) is consistent with previous register data on non-Western immigrants to Norway [38]. Insulin-resistant diabetes is reported to be associated with morbidity in cancer [39]. Hence, an explanation for the lower rates in non-Western immigrants may be related to type of diabetes, with lower prevalence of insulin-resistant diabetes in people of nonWestern origin [3], but this remains to be further investigated.

One may argue that the 'healthy migrant effect', indicating that people migrating represent those most able to move and thus a healthier group compared with those not migrating [40, 41], may influence our findings. Although immigrants may have better health in relation to the conditions in their home country, their general mental and physical health in relation to the native Swedish population is generally not better [42]. We do not have data on the number of immigrants included in the study that have moved back and not returned; however, a database register study of refugees to Denmark from 1993 to 2010 did not show indications of remigration bias, but rather supported the opposite [41]. Due to the vulnerable political and economic situations that a large part of non-Western populations are exposed to, in combination with access to the Swedish health system where one gets treatment regardless of income or socioeconomic situation, we do not consider it likely that 'salmon bias' has influenced our data.

The strengths of this study are the sample size, the study design, the thorough sampling and the recent collection of data. The data were collected from national databases, including registers of drug prescription, socioeconomic status and mortality, and including all individuals in Sweden. Since socioeconomic vulnerability represents a strong determinant for migrant mortality from diabetes [43], all data in this study were adjusted for several variables reflecting socioeconomic burden. Although our data were adjusted for age at onset, we may not have been able to fully adjust for the large age difference (approximately 1.5 decades) between non-Western immigrants and native Swedes. Also, the older Swedish cohort may have a heavier cluster of comorbidities influencing survival rates. Our data lack information on metabolic control, comorbidities and related drug treatment, and lifestyle factors 
such as physical activity, diet, tobacco smoking and alcohol consumption impacting CVD risk and survival. We do not think this has influenced the outcome of our data since our results are consistent with previous data in Sweden on firstgeneration immigrants with type 2 diabetes [12]. Further, if the younger age at onset could explain differences in survival rates, we would expect similar results in second-generation immigrants as in first-generation immigrants, which we do not see. The power of a survival analysis is related to the number of events, and simulation work has suggested at least ten outcome events per predictor in the model [44], although sometimes this rule can be relaxed [45]. Due to the low number of events (ESM Fig. 4) in some subgroups, analysis of mortality is limited by low statistical power and so evidence is inconclusive in these groups.

The findings of this nationwide study of all people with type 2 diabetes in Sweden raise concerns regarding the erosion of life years to which non-Western immigrants with diabetes acculturating to the Western culture are exposed. From a clinical perspective, it is important to focus awareness on secondgeneration immigrants with diabetes to optimise nonpharmacological and pharmacological prevention to improve metabolic control and reduce the risk of diabetic complications. Future intervention studies of first- and second-generation nonWestern immigrants are needed to increase the understanding of contributing mechanisms to mortality advantage, lifestyle and genetic contributions, and epigenetic interactions.

Acknowledgements We acknowledge K. Fall (Clinical Epidemiology and Biostatistics, School of Medical Sciences, Örebro University, Sweden) for assisting with data management.

Data availability The data that support the findings of this study are available from the National Board of Health and Welfare, Statistics Sweden and the Swedish National Diabetes Register, but restrictions apply to the availability of these data, which were used under license for the current study and so are not publicly available.

Funding Open access funding provided by Lund University. This study was funded by grants from LUDC and the Swedish Research Council (Exodiab, Linnégrants); Lund University (ALF grants); the Västerbotten County Council (OR); and the University Health Care Research Center Örebro, Sweden.

Authors' relationships and activities The authors declare that there are no relationships or activities that might bias, or be perceived to bias, their work.

Author contributions LB contributed to the design of the study, research aims, acquisition of data, data analysis, data interpretation, and writing and drafting of the article. RU contributed to design of the study, statistical analysis, interpretation of the data and writing of the manuscript. CJÖ contributed to the design of the study, data analysis and interpretation of the data. OR contributed to the design of the study, data analysis and interpretation of the data. SJ contributed to acquisition of data, the design of the study, data analysis and interpretation of the data, and writing of the manuscript. PW contributed to acquisition of data, design of the study, data analysis and interpretation of the data, and writing of the manuscript. All authors contributed to drafting of the article, revising it critically and finally approving the version to be submitted. SJ is the guarantor of this work and is responsible for its integrity.

Open Access This article is licensed under a Creative Commons Attribution 4.0 International License, which permits use, sharing, adaptation, distribution and reproduction in any medium or format, as long as you give appropriate credit to the original author(s) and the source, provide a link to the Creative Commons licence, and indicate if changes were made. The images or other third party material in this article are included in the article's Creative Commons licence, unless indicated otherwise in a credit line to the material. If material is not included in the article's Creative Commons licence and your intended use is not permitted by statutory regulation or exceeds the permitted use, you will need to obtain permission directly from the copyright holder. To view a copy of this licence, visit http://creativecommons.org/licenses/by/4.0/.

\section{References}

1. International Diabetes Federation (2019) Complications. Available from https://www.idf.org/aboutdiabetes/complications.html. Accessed 11 June 2020

2. Marshall SM, Flyvbjerg A (2006) Prevention and early detection of vascular complications of diabetes. BMJ 333(7566):475-480. https://doi.org/10.1136/bmj.38922.650521.80

3. Sattar N, Gill JM (2015) Type 2 diabetes in migrant south Asians: Mechanisms, mitigation, and management. Lancet Diabetes Endocrinol 3(12):1004-1016. https://doi.org/10.1016/S22138587(15)00326-5

4. Wandell PE, Carlsson A, Steiner KH (2010) Prevalence of diabetes among immigrants in the Nordic countries. Curr Diabetes Rev 6(2): 126-133. https://doi.org/10.2174/157339910790909404

5. Franks PW, Pearson E, Florez JC (2013) Gene-environment and gene-treatment interactions in type 2 diabetes: Progress, pitfalls, and prospects. Diabetes Care 36(5):1413-1421. https://doi.org/10. 2337/dc12-2211

6. Lyssenko V, Jonsson A, Almgren P et al (2008) Clinical risk factors, DNA variants, and the development of type 2 diabetes. $\mathrm{N}$ Engl J Med 359(21):2220-2232. https://doi.org/10.1056/ NEJMoa0801869

7. Wändell PE (2013) Population groups in dietary transition. Food Nutr Res 57. https://doi.org/10.3402/fnr.v57i0.21668

8. Marmot M, Friel S, Bell R, Houweling TA, Taylor S (2008) Closing the gap in a generation: Health equity through action on the social determinants of health. Lancet. 372(9650):1661-1669. https://doi.org/10.1016/S0140-6736(08)61690-6

9. Wemrell M, Bennet L, Merlo J (2019) Understanding the complexity of socioeconomic disparities in type 2 diabetes risk: A study of 4.3 million people in Sweden. BMJ Open Diabetes Res Care 7(1): e000749. https://doi.org/10.1136/bmjdrc-2019-000749

10. White JS, Hamad R, Li X et al (2016) Long-term effects of neighbourhood deprivation on diabetes risk: Quasi-experimental evidence from a refugee dispersal policy in Sweden. Lancet Diabetes Endocrinol 4(6):517-524. https://doi.org/10.1016/ S2213-8587(16)30009-2

11. Rawshani A, Svensson AM, Rosengren A, Zethelius B, Eliasson B, Gudbjörnsdottir S (2015) Impact of ethnicity on progress of glycaemic control in 131,935 newly diagnosed patients with type 
2 diabetes: A nationwide observational study from the Swedish National Diabetes Register. BMJ Open 5(6):e007599. https://doi. org/10.1136/bmjopen-2015-007599

12. Rawshani A, Svensson AM, Zethelius B, Eliasson B, Rosengren A, Gudbjörnsdottir S (2016) Association between socioeconomic status and mortality, cardiovascular disease, and cancer in patients with type 2 diabetes. JAMA Intern Med 176(8):1146-1154. https:// doi.org/10.1001/jamainternmed.2016.2940

13. Wallace M, Khlat M, Guillot M (2019) Mortality advantage among migrants according to duration of stay in France, 2004-2014. BMC Public Health 19(1):327

14. Vandenheede H, Willaert D, De Grande H, Simoens S, Vanroelen C (2015) Mortality in adult immigrants in the 2000s in Belgium: A test of the 'healthy-migrant' and the 'migration-as-rapid-health-transition' hypotheses. Tropical Med Int Health 20(12):1832-1845

15. Syse A, Dzamarija MT, Kumar BN, Diaz E (2018) An observational study of immigrant mortality differences in Norway by reason for migration, length of stay and characteristics of sending countries. BMC Public Health 18(1):508

16. Wettermark B, Hammar N, Fored CM et al (2007) The new Swedish Prescribed Drug Register-Opportunities for pharmacoepidemiological research and experience from the first six months. Pharmacoepidemiol Drug Saf 16(7):726-735

17. Jansson SP, Fall K, Brus O et al (2015) Prevalence and incidence of diabetes mellitus: A nationwide population-based pharmaco-epidemiological study in Sweden. Diabet Med 32(10):1319-1328. https://doi.org/10.1111/dme.12716

18. Jansson SP, Andersson DK, Svardsudd K (2007) Prevalence and incidence rate of diabetes mellitus in a Swedish community during 30 years of follow-up. Diabetologia 50(4):703-710. https://doi.org/ 10.1007/s00125-007-0593-4

19. Ludvigsson JF, Svedberg P, Olen O, Bruze G, Neovius M (2019) The longitudinal integrated database for health insurance and labour market studies (LISA) and its use in medical research. Eur J Epidemiol 34(4): 423-437. https://doi.org/10.1007/s10654-019-00511-8

20. Brooke HL, Talback M, Hornblad J et al (2017) The Swedish cause of death register. Eur J Epidemiol 32(9):765-773. https://doi.org/ 10.1007/s10654-017-0316-1

21. Royston P, Sauerbrei W (2005) Building multivariable regression models with continuous covariates in clinical epidemiology-With an emphasis on fractional polynomials. Methods Inf Med 44(4): $561-571$

22. Harrell FE Jr, Lee KL, Califf RM, Pryor DB, Rosati RA (1984) Regression modelling strategies for improved prognostic prediction. Stat Med 3(2):143-152. https://doi.org/10.1002/sim.4780030207

23. Okrainec K, Bell CM, Hollands S, Booth GL (2015) Risk of cardiovascular events and mortality among a population-based cohort of immigrants and long-term residents with diabetes: Are all immigrants healthier and if so, for how long? Am Heart J 170(1):123132. https://doi.org/10.1016/j.ahj.2015.04.009

24. Antecol H, Bedard K (2006) Unhealthy assimilation: Why do immigrants converge to American health status levels? Demography. 43(2): 337-360. https://doi.org/10.1353/dem.2006.0011

25. De Maio FG, Kemp E (2010) The deterioration of health status among immigrants to Canada. Glob Public Health 5(5):462-478. https://doi.org/10.1080/17441690902942480

26. Bennet L, Groop L, Lindblad U, Agardh CD, Franks PW (2014) Ethnicity is an independent risk indicator when estimating diabetes risk with FINDRISC scores: A cross sectional study comparing immigrants from the Middle East and native Swedes. Prim Care Diabetes 8(3):231-238. https://doi.org/10.1016/j.pcd.2014.01.002
27. Tran AT, Berg TJ, Gjelsvik B et al (2019) Ethnic and gender differences in the management of type 2 diabetes: A cross-sectional study from Norwegian general practice. BMC Health Serv Res 19(1):904

28. Rawshani A, Franzén S, Eliasson B et al (2017) Mortality and cardiovascular disease in type 1 and type 2 diabetes. N Engl J Med 376(15): 1407-1418. https://doi.org/10.1056/NEJMoa1608664

29. World Health Organization. Regional Office for Europe (2013) Health literacy: the solid facts. Available from https://apps.who. int/iris/handle/10665/326432. Accessed 11 June 2020.

30. Rao Kondapally Seshasai S, Kaptoge S, Thompson A et al (2011) Diabetes mellitus, fasting glucose, and risk of cause-specific death. N Engl J Med 364(9):829-841. https://doi.org/10.1056/ NEJMoa1008862

31. Bennet L, Nilsson PM (2014) Country of birth modifies the associations of body mass and hemoglobin A1c with office blood pressure in Middle Eastern immigrants and native Swedes. J Hypertens 32(12):2362-2370; discussion 2370. https://doi.org/10.1097/HJH. 000000000000345

32. Kumar BN, Selmer R, Lindman AS, Tverdal A, Falster K, Meyer HE (2009) Ethnic differences in SCORE cardiovascular risk in Oslo, Norway. Eur J Cardiovasc Prev Rehabil 16(2):229-234. https://doi.org/10.1097/HJR.0b013e3283294b07

33. Lyssenko V, Almgren P, Anevski D et al (2005) Predictors of and longitudinal changes in insulin sensitivity and secretion preceding onset of type 2 diabetes. Diabetes 54(1):166-174

34. Ahlqvist E, Storm P, Karajamaki A et al (2018) Novel subgroups of adult-onset diabetes and their association with outcomes: A datadriven cluster analysis of six variables. Lancet Diabetes Endocrinol 6(5):361-369. https://doi.org/10.1016/S2213-8587(18)30051-2

35. Edqvist J, Rawshani A, Adiels M et al (2018) BMI and mortality in patients with new-onset type 2 diabetes: A comparison with ageand sex-matched control subjects from the general population. Diabetes Care 41(3):485-493. https://doi.org/10.2337/dc17-1309

36. Ortega FB, Lee DC, Katzmarzyk PT et al (2013) The intriguing metabolically healthy but obese phenotype: Cardiovascular prognosis and role of fitness. Eur Heart J 34(5):389-397. https://doi.org/ 10.1093/eurheartj/ehs174

37. Al-Majdoub M, Spegel P, Bennet L (2020) Metabolite profiling paradoxically reveals favorable levels of lipids, markers of oxidative stress and unsaturated fatty acids in a diabetes susceptible group of Middle Eastern immigrants. Acta Diabetol 57(5):597-603. https://doi.org/10.1007/s00592-019-01464-w

38. Thogersen H, Moller B, Robsahm TE, Babigumira R, Aaserud S, Larsen IK (2018) Differences in cancer survival between immigrants in Norway and the host population. Int J Cancer 143(12): 3097-3105. https://doi.org/10.1002/ijc.31729

39. Giovannucci E, Harlan DM, Archer MC et al (2010) Diabetes and cancer: A consensus report. Diabetes Care 33(7):1674-1685. https://doi.org/10.2337/dc10-0666

40. Norredam M, Agyemang C, Hoejbjerg Hansen OK et al (2014) Duration of residence and disease occurrence among refugees and family reunited immigrants: Test of the 'healthy migrant effect' hypothesis. Tropical Med Int Health 19(8):958-967. https://doi. org/10.1111/tmi.12340

41. Norredam M, Hansen OH, Petersen JH et al (2015) Remigration of migrants with severe disease: Myth or reality? - A register-based cohort study. Eur J Pub Health 25(1):84-89. https://doi.org/10. 1093/eurpub/cku138

42. Bennet L, Lindstrom M (2018) Self-rated health and social capital in Iraqi immigrants to Sweden: The MEDIM population-based study. Scand J Public Health 46(2):194-203. https://doi.org/10. $1177 / 1403494817730997$ 
43. Vandenheede H, Deboosere P, Stirbu I et al (2012) Migrant mortality from diabetes mellitus across Europe: The importance of socioeconomic change. Eur J Epidemiol 27(2):109-117. https://doi.org/ 10.1007/s10654-011-9638-6

44. Bradburn MJ, Clark TG, Love SB, Altman DG (2003) Survival analysis part III: Multivariate data analysis - Choosing a model and assessing its adequacy and fit. Br J Cancer 89(4):605-611. https://doi.org/10.1038/sj.bjc.6601120
45. Vittinghoff E, McCulloch CE (2007) Relaxing the rule of ten events per variable in logistic and Cox regression. Am J Epidemiol 165(6): 710-718. https://doi.org/10.1093/aje/kwk052

Publisher's note Springer Nature remains neutral with regard to jurisdictional claims in published maps and institutional affiliations. 